\title{
INOVAÇÃO EM SERVIÇO ORIENTADA PARA GESTÃO DE RESÍDUOS: ESTUDO DE CASO EM UMA PRESTADORA DE SERVIÇOS NA REGIÃO METROPOLITANA DE BELO HORIZONTE
}

\author{
SERVICE INNOVATION FOR WASTE MANAGEMENT: A CASE STUDY OF A SERVICE PROVIDER IN THE \\ METROPOLITAN REGION OF BELO HORIZONTE
}

INNOVACIÓN EN SERVICIO ORIENTADA PARA LA GESTIÓN DE RESIDUOS: ESTUDIO DE CASO EN UNA PROVEEDORA DE SERVICIOS EN LA REGIÓN METROPOLITANA DE BELO HORIZONTE

\author{
EDER JUNIOR ALVES \\ Doutor \\ Universidade Federal de Minas Gerais - Brasil \\ Instituto de Gestão de Tecnologia da Informação - Brasil \\ ederj@yahoo.com \\ ORCID: http://orcid.org/0000-0002-2000-4653 \\ CARLOS ALBERTO GONÇALVES \\ Doutor \\ Universidade Federal de Minas Gerais - Brasil \\ FUMEC - Brasil \\ carlos@face.ufmg.br \\ ORCID: http://orcid.org/0000-0003-1222-141X \\ Submetido em: 18/01/2018 \\ Aprovado em: 14/03/2019
}

Doi: alcance.v26n1(Jan/Abr).p094-109

\section{RESUMO}

É consabido que a Construção Civil provoca externalidades de grande monta no ambiente. Este artigo contribui para a área da Responsabilidade Social Corporativa (RSC) em organizações, buscando inovações que reduzam os impactos provocados por resíduos da Construção Civil na sociedade. O objetivo deste artigo é analisar a estruturação empresarial e melhores práticas em uma organização de pequeno porte que oferece inovação em serviço, orientada para gestão de resíduos, possibilitando descobrir quais melhorias podem ser implementadas neste processo evolutivo. Trata-se de um estudo de caso que teve as entrevistas participativas e a análise documental como instrumentos habilitadores. A organização escolhida conquistou prêmios devido a sua oferta de serviços inovadores que apoiam a gestão de resíduos da Construção Civil. Os resultados foram analisados sob a perspectiva da inovação, da RSC e da teoria dos stakeholders. Conclui-se que uma organização inova quando busca continuar agregando valor, transformando constrangimento ambiental em novos negócios. Pode-se alcançar melhores práticas em gestão dos resíduos por meio do conhecimento e das lições aprendidas e desenvolvidas por meio de um repositório que coleta, armazena e distribui informações sobre experiências em projetos. Por fim, é possível melhorar a confecção dos contratos, disponibilizando-os para consultas pelas partes interessadas e possibilitando melhor controle das tarefas.

Palavras-chave: Inovação. Responsabilidade social corporativa. Partes interessadas. Gestão de resíduos.

\section{ABSTRACT}

It is common knowledge that civil construction industry causes large externalities in the environment. This article contributes to the area of corporate social responsibility in organizations seeking innovations that reduce the 
impacts caused by construction waste in society. The objective of this article is to analyze the business structuring and best practices in a small organization that offers innovation in service oriented to waste management, seeking to discover which improvements can be implemented in this evolutionary process. It is a case study that involved participatory interviews and documentary analysis as enabling instruments. The chosen organization won an award due to its offer of innovative services that support waste management in the construction industry. The results were analyzed from the perspectives of innovation, RSC, and Stakeholder Theory. In conclusion, an organization innovates when it seeks to continue adding value, transforming environmental constraints into new business. Best practices in waste management can be achieved through the knowledge and lessons learned and developed through a repository that collects, stores and distributes information about experiences in projects. Finally, it is possible to improve the preparation of the contracts, making them available for consultation by interested parties and enabling better control of tasks.

Keywords: Innovation. Corporate social responsibility. Stakeholders. Waste management.

\section{RESUMEN}

Es del conocimiento común que la Construcción Civil causa grandes externalidades en el medio ambiente. Este artículo contribuye para el área de la Responsabilidad Social Corporativa (RSC) en organizaciones buscando innovaciones que reduzcan los impactos provocados por residuos de la Construcción Civil en la sociedad. El objetivo de este artículo es analizar la estructura del negocio y las mejores prácticas en una organización pequeña que ofrece innovación en el servicio orientado a la gestión de residuos, lo que permite descubrir qué mejoras se pueden implementar en este proceso evolutivo. Es un estudio de caso que tuvo entrevistas participativas y análisis documental como instrumentos habilitadores. La organización elegida ganó el premio debido a su oferta de servicios innovadores que apoyan la gestión de residuos de la Construcción Civil. Los resultados fueron analizados sobre la perspectiva de la innovación, RSC y teoría de las partes interesadas. En conclusión, una organización innova cuando busca continuar agregando valor, transformando la restricción ambiental en nuevos negocios. Las mejores prácticas en la gestión de residuos se pueden lograr a través del conocimiento y las lecciones aprendidas desarrolladas a través de un repositorio que recopila, almacena y distribuye información sobre experiencias en proyectos. Finalmente, es posible mejorar la preparación de los contratos, poniéndolos a disposición de las partes interesadas para su consulta y permitiendo un mejor control de las tareas.

Palabras clave: Innovación. Responsabilidad social corporativa. Partes interesadas. Gestión de residuos.

\section{INTRODUÇÃO}

No contexto da sustentabilidade ambiental, pode-se atribuir vínculos que estruturam a obtenção de vantagem competitiva das organizações, entre eles, incentivo às eficiências, atração de clientes e obtenção de novos negócios (Walsh \& Dodds, 2017). Recursos ambientais permitem melhor desempenho financeiro das firmas, sustentando a vantagem competitiva e aprimorando os efeitos positivos por meio de maiores margens de lucro (Yadav, Han \& Kim, 2017). Evidências que apoiam estas posições podem ser encontradas em Tsai e Liao (2017), os autores apontam que a demanda do mercado modera positivamente a relação entre a estratégia ambiental e a inovação ecológica, ou inovações praticadas nas relações das firmas com o meio ambiente (aqui chamada de "eco inovação").

Como resultado, a ecoinovação pode ser um caminho na busca de soluções inovadoras para problemas causados ao ambiente, produção de externalidades negativas, decorrentes das operações das firmas. Em especial, este trabalho tem como objeto observar e analisar os processos de descarte de resíduos sólidos da Construção Civil. Assim, propõe-se a descobrir quais melhorias e inovações podem ser implementadas em organizações, buscando oferecer produtos e serviços que acomodam boas práticas da gestão ambiental, ampliando a estratégia organizacional dos seus clientes. De forma geral, estas melhores práticas podem ampliar a Weltanschauung - visão de mundo das funções executivas nas lidas com as relações das firmas e o meio ambiente. Evidente que a consciência das ações se dá no ambiente da firma e nos órgãos de regulação, representando os stakeholders (partes interessadas) indiretos, como o meio ambiente, que não tem assento nos conselhos de administração. E nessa relação, a sociedade, como parte interessada indireta, agradece pela responsabilidade assumida pela díade Firma - Órgão regulador. 
Trumpp e Guenther (2017) estudaram diversas organizações e encontraram evidências empíricas de uma relação não linear entre a quantidade de resíduos produzidos e a lucratividade da firma. Surge uma nova ética que ultrapassa a obtenção de lucros, mas que jaz relacionada com a mudança de comportamento da sociedade em relação ao desempenho organizacional e benefícios do relacionamento aberto e direto com todas as partes afetadas pelos processos produtivos das organizações e dos seus resíduos industriais. Trata-se da responsabilidade e da preocupação com a gestão socioambiental numa perspectiva abrangente. Carrol (1991) propôs uma Responsabilidade Social Corporativa (RSC) que envolve as realizações simultâneas de comprometimento em vários aspectos, econômico, legal, ético e filantrópico.

Em 2010, o Brasil instituiu o Política Nacional dos Resíduos Sólidos (PNRS) no Formulário de Referência (FR) e no Relato Integrado (RI), evidenciando e ratificando a Responsabilidade Social Corporativa (RSC) em relação à gestão de resíduos sólidos e estabeleceu que as empresas devem promover o acesso à informação às partes interessadas. Entretanto, apesar da ocorrência de incrementos na universalização dos serviços em municípios como do Rio de Janeiro, a "maioria dos objetivos da PNRS não só é desconsiderada, como também não possui diretrizes políticas ao nível local para serem encaminhadas e monitoradas" (Maiello, Britto \& Valle, 2018, p. 24). Silva e Biernaski (2018) relatam a grande necessidade de ações no entorno metropolitano de Belo Horizonte na busca de redução do consumo de recursos naturais não renováveis e volume de resíduos, visto que o crescimento urbano gera cada vez mais lixo e resíduos originados deste fenômeno.

Destarte, os procedimentos metodológicos realizados na pesquisa objetivaram analisar e compreender a estrutura empresarial da firma prestadora de serviços escolhida para o estudo de caso, observando os resultados sob a perspectiva da inovação, RSC e teoria das partes interessadas. Não obstante, buscou-se descobrir as melhores práticas dentro desta organização, que oferta serviços inovadores orientados para a gestão de resíduos na região metropolitana de Belo Horizonte, possibilitando, assim, descobrir quais melhorias podem ser implementadas por empresas similares.

É importante notar que este estudo possibilitou obter considerações no âmbito exploratório da unidade de análise. A escolha da empresa ocorreu como desdobramento da análise das práticas e dos resultados obtidos pela organização no mercado, considerando o destaque da sua orientação a inovação ecológica. Um aspecto igualmente significativo foi sua premiação na categoria serviços sustentáveis em concurso internacional.

\section{FUNDAMENTAÇÃO TEÓRICA}

Desde que o relatório de Brundtland (1987) foi publicado pela Comissão Mundial de Meio Ambiente e Desenvolvimento, a sustentabilidade passou a ter melhor aceitação nas organizações como instrumento habilitador da satisfação de necessidades internas e externas. A satisfação dos clientes e a correta alocação dos recursos não precisam estar vinculadas com processos produtivos que comprometam a sobrevivência das gerações futuras. Sucesso econômico nos negócios não deve prejudicar o equilíbrio social e ambiental decorrente das ações das firmas. A sustentabilidade das organizações é construída por avanços gradativos em leis, regulamentos, padrões ambientais e no pensamento crítico dos tomadores de decisões na estrutura organizacional. Elkington (1997) argumenta que a sustentabilidade só será possível caso ocorra equilíbrio entre os aspectos econômico, social e ambiental.

O conceito de desenvolvimento sustentável no meio organizacional pauta na adoção de gerenciamento ecoeficiente, práticas identificadas com a eficiência ecológica e sistemas produtivos obedecendo a deliberações estratégicas voltadas para a inovação, responsabilidade social corporativa e gestão das partes interessadas. Além disso, os resultados indicam que a intensidade da inovação afeta o efeito da estratégia ambiental sobre a ecoinovação, mas a direção da influência varia com as diferentes categorias (Tsai \& Liao, 2017). Donadon e Santos (2018) analisaram o resultado do processo de ecoinovação voltado aos resíduos sólidos industriais (biomassa) de processamento de manga, concluindo que a adaptação das antigas caldeiras para funcionamento via automação com queimadores de pellets, a utilização da biomassa vegetal como fonte alternativa de energia limpa e a agregação de valor econômico no aproveitamento das cinzas da caldeiraria como adubo constituem em ações ecoinovadoras incrementais.

\subsection{INOVAÇÃO}

Norrman e Bager-Sjögren (2010) afirmam que, para as organizações chegarem ao estágio de 
desenvolvimento adequado, precisam de uma rede que seja colaborativa, resultando na formação de uma cadeia de fornecedores. Os autores comentaram que as ações embutidas nas políticas públicas para apoiar o crescimento do pequeno empreendedor devem ser oferecidas nas fases iniciais da organização, suportando a comercialização de seus produtos e serviços. Nesta perspectiva, mais do que exercerem o papel de comando e controle, os governos podem estimular as organizações a adotarem métodos mais sustentáveis. Norrman e Bager-Sjögren (2010) defendem que estas políticas públicas ajudariam a colocar as organizações no caminho das vendas, pavimentando a estrada do desenvolvimento sustentável e do crescimento.

Este crescimento organizacional apontado por Norrman e Bager-Sjögren (2010) pode ser explicado pela forma como as inovações são alcançadas. Veeraraghavan (2009) sugere uma combinação de muitos fatores como fundamentais na tarefa de empreender, incluindo o histórico familiar, habilidade para assumir riscos e forma de colocar novas ideias para serem realizadas. 0 empreendedor precisa de características distintas: jeito para tratar riscos e conhecimento sobre a destruição criativa (Schumpeter,1934). Joseph Schumpeter propõe que a inovação está associada ao que diferencia a organização diante da concorrência.

Beck (2010) reflete sobre a lógica da produção de riqueza que cria riscos, relatando que as promessas de progresso científico, melhores condições de vida e dignidade ao homem não foram concretizadas. Nos tempos atuais, os perigos ultrapassam fronteiras fictícias impostas por soberanias nacionais, aumentando a preocupação com os efeitos gerados pela exploração dos recursos naturais.

Outro ponto de atenção está na concorrência do mercado, que passou a ser global na contemporaneidade, entretanto as organizações lucram mais colaborando do que competindo. Segundo Tödling e Kaufmann (2001), pequenas e médias empresas podem ser condutoras de inovações radicais, se existirem precondições específicas em uma região. Estas premissas podem ser observadas em parques tecnológicos ou incubadoras.

Estas organizações "visam fomentar e promover sinergias nas atividades de pesquisa científica, tecnológica e inovação entre organizações, instituições científicas e tecnológicas através do apoio dos governos comunidade local e setor privado" (Mdic, 2015, p.1). Os clusters formados criam um ambiente cooperativo e fornece a infraestrutura para o desenvolvimento e para a interação de empresas, universidades e institutos de pesquisa.

Desta forma, as organizações, buscando crescimento e desempenho, precisam compreender que, para construir organizações inovadoras, é preciso atenção aos papéis e aos cargos exercidos pelos indivíduos. Segundo Tidd, Bessant e Pavitt (2005), treinamento e desenvolvimento da equipe, a maneira como as pessoas se envolvem com a inovação, a situação da organização em relação à aprendizagem e o compartilhamento do conhecimento são fatores relevantes. Penrose (1959) argumentou sobre a importância do conhecimento para 0 crescimento organizacional.

A este respeito, Stamm e Trifilova (2009) ressaltaram que o futuro das organizações será inovar ou ir à falência. Segundo as autoras, pessoas e organizações irão sempre repensar o caminho como as coisas são feitas no presente e haverá novas ideias. As inovações são temporárias. Govindarajan e Trimble (2005) comentaram que, para crescer, as organizações necessitam ênfase nas tarefas diárias, avançando em ideias para a execução de novos projetos.

Kanter (1999) afirma que, para obter sucesso nos negócios, é preciso inovar. Em ambientes de incerteza proposto na sociedade do risco de Beck (2010), o sucesso vem do desenvolvimento de tecnologia com base em inovações perenes por meio da criação do conhecimento e da internalização deste processo criativo de Schumpeter (1934). Em Kanter (1999), percebe-se o vínculo da inovação com a RSC. Segundo a autora, existem organizações que buscam novas fontes de inovação por meio da inspiração no setor social, incluindo escolas públicas e programas de bem-estar no trabalho.

Há, portanto, um novo paradigma emergente para a inovação proposto por Stamm e Trifilova (2009), em que a relação do futuro da inovação está relacionada com o acesso à água limpa para todos, saúde, comida, redução de emissões de $\mathrm{CO} 2$, redução da pobreza e busca pela paz. Segundo as autoras, os detentores do poder não devem pensar na inovação para si, mas sim voltada para o bem comum.

Segundo Radu e Francoeur (2017), em tempos de baixos níveis de desempenho ambiental, organizações inovadoras tendem a informar suas partes interessadas sobre sua inovação e estratégia para obter um melhor desempenho ambiental do que suas concorrentes. Essa diferença de divulgação tende a diminuir, à medida que as empresas inovadoras alcançam melhores resultados ambientais (Radu \& Francoeur, 2017). Os autores relatam 
que níveis altos de divulgação ambiental estão associados ao desempenho ambiental das organizações estudadas.

\subsection{RESPONSABILIDADE SOCIAL CORPORATIVA}

A estratégia organizacional para inovar relaciona-se, entre outros fatores, como o empreendedorismo. Desde o lançamento do livro de Chester Barnard, publicado em 1938, A Função do Executivo, o tema RSC vem sendo abordado na ótica dos sistemas colaborativos entre as organizações. Os fatores psicológicos e sociais envolvidos na eficiência da cooperação foram analisados por Barnard (1971), enfatizando a importância do condicionamento social de todos os que participam e dos que não participam. Assim, "fatores sociais estão sempre presentes na cooperação, não só devido à natureza deste sistema, como pelo efeito da experiência social sob indivíduos e seus motivos" (BARNARD, 1971, p.70).

Em 1953 o livro Social Responsibilities of the Businessman de Howard R. Bowen já abordava esta temática. Bowen (1953) definiu a RSC como obrigações do homem de negócios para perseguir políticas, tomar decisões ou seguir linhas de ações que são desejáveis em termos dos objetivos e dos valores do homem na sociedade.

No final da década de 1979, Ashley Carrol propôs um dos modelos mais desatacados de RSC, descrevendo a responsabilidade das organizações com as perspectivas de responsabilidades econômicas, legais, éticas e voluntárias inerentes ao funcionamento e ao exercício de suas finalidades. Carrol (1991) aprimora o modelo incorporando o enfoque das partes interessadas, no qual as responsabilidades empresariais podem ser representadas em modelo no formato de pirâmide. A Figura 1 apresenta a pirâmide de Carrol (1991) para RSC. Os níveis da pirâmide foram nomeados segundo as perspectivas econômica, legal, ética e filantrópica.

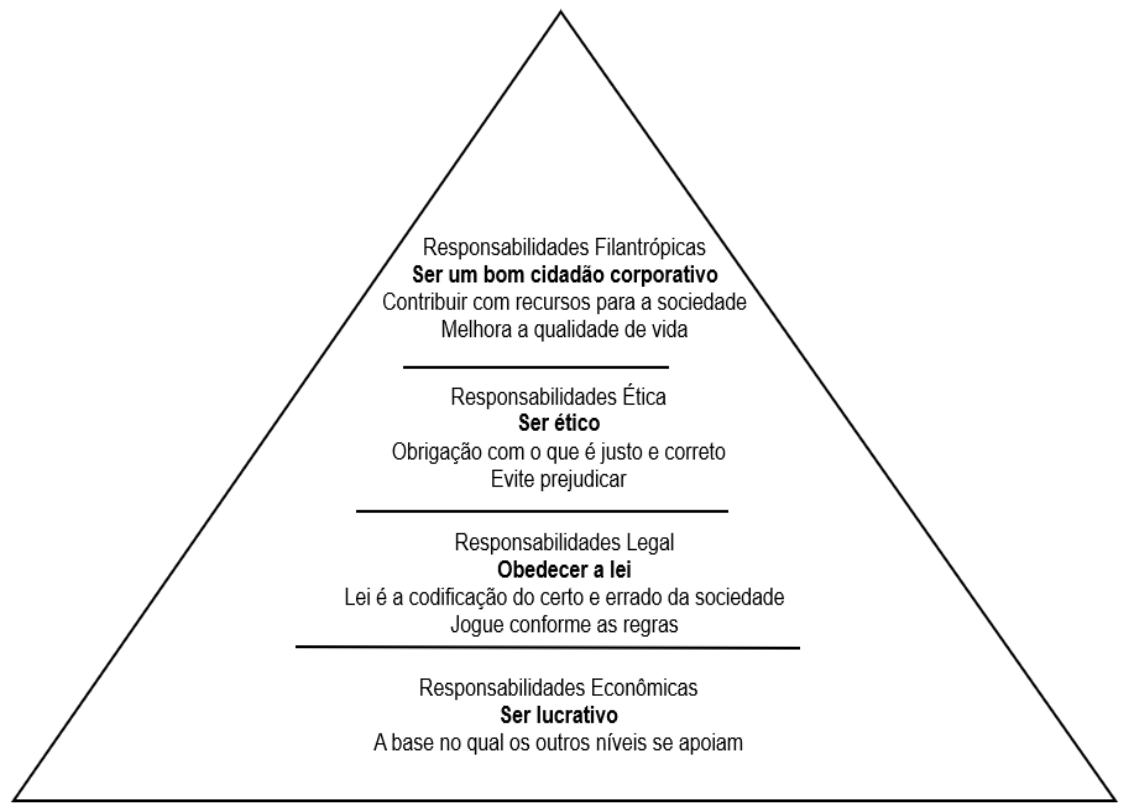

Figura 1. A pirâmide da Responsabilidade Social Corporativa.

Fonte: Adaptada de Carrol (1991, p.42).

A responsabilidade econômica tem como declarações atuar de forma constante, maximizando os resultados. Deve ser comprometida com a lucratividade, manter posição competitiva forte, ter alto nível de eficiência operacional e vincular o sucesso da organização com lucros consistentes (CARROL, 1991).

Na responsabilidade legal, segundo nível da pirâmide, busca-se desempenho com as leis. É necessário cumprir várias regulações federais, estaduais e locais, fornecendo produtos e serviços que atendam aos requisitos legais.

Organizações, ao adotarem a responsabilidade ética, devem operar conforme os costumes sociais e as normas éticas, reconhecendo e respeitando novos envolvimentos éticos ou normas morais adotados pela 
sociedade. Segundo Carrol (1991), torna-se relevante ter uma boa cidadania corporativa, definida como moralmente e eticamente correta.

Somente no topo da pirâmide encontra-se a responsabilidade filantrópica, em que as ações das organizações direcionam para atuação na caridade e na filantropia. É relevante apoiar a execução de eventos de artes ou ter colaboradores participando de atividades de caridade e voluntariado em comunidades locais. 0 fornecimento de assistência para instituições de ensino públicas e privadas ou apoio em projetos que aumentam a qualidade de vida da comunidade são ações na busca por filantropia.

Uma argumentação contrária pode ser encontrada em Friedman (1984), que defendia a necessidade em satisfazer acionistas, buscando aumentar os benefícios econômicos. A escola de Friedman e outras correntes tradicionais propõem aumentar ao máximo o retorno sobre 0 investimento dos proprietários do negócio. Subsequentemente, uma estratégia corporativa para melhorar o desempenho ambiental demonstra a responsabilidade da administração de maximizar a riqueza dos acionistas (Yadav, Han \& Kim 2017).

De acordo com Habib e Bhuiyan (2017), existem penalidades monetárias para o desempenho ambiental deficiente. Os autores analisaram dados da Bloomberg sobre as penalidades monetárias impostas a empresas na União Europeia (UE) que tiveram um desempenho fraco nos aspectos ambientas da RSC, descobrindo que empresas com altos níveis de emissões de gases de efeito estufa e de resíduos perigosos são mais propensas a receber penalidades monetárias.

No ambiente brasileiro, após o PNRS, a responsabilidade pela gestão, que antes era somente do município, passa a ser compartilhada com todos os atores envolvidos na manipulação de resíduos, desde a fabricação até a destinação final (Ferreira, 2018). Esta legislação estabeleceu para a união e para os estados, por meio de suporte técnico e financeiro, a viabilização de projetos ambientais. Ferreira (2018) analisou os resíduos urbanos no estado do Paraná e apontou que, no período pesquisado, houve avanço nas etapas de gestão, como coleta seletiva, destinação final e eliminação de lixões a céu aberto.

Neste contexto, a RSC é um tema atual para os negócios e mídia no Brasil e no mundo, existindo uma demanda crescente por divulgação ambiental confiável para uma ampla gama de partes interessadas. Os desempenhos ético, social e ambiental são considerados importantes pelas partes interessadas e, portanto, são ativamente examinados por elas. Tais interessados esperam que as informações dos relatórios sejam confiáveis e avaliem corretamente o desempenho organizacional (Radu \& Francoeur, 2017) em termos éticos, bem como sociais e ambientais.

\subsection{PARTES INTERESSADAS}

A proposição de RSC apresentada por Carrol (1991) é bem-aceita na academia, como atestam considerações apresentadas pelos seus pares. Contudo, Bakker, Groenewegen \& Hond (2005) analisaram a RSC por meio de um estudo bibliométrico e concluíram que existe uma tendência em criar novas proposições. Carrol e Buchholtz (2006) enfatizam que a capacidade das firmas para responder questões sociais evoluiu por meio da adoção da RSC. Estes conceitos amadurecidos fomentaram o início para com o gerenciamento das partes interessadas.

A visão focada nos acionistas de Friedman (1984) foi contestada por autores que defendem melhor planejamento para interagir com todas as partes interessadas, não apenas os acionistas. Chega-se, portanto, ao conceito de partes interessadas, "grupos ou indivíduos que afetam ou são afetados pelas realizações dos objetivos da organização" (FREEMAN, 1984, p.48). Nesta abordagem, as organizações possuem responsabilidades com 0 aspecto social, tanto com o público interno, quanto externo. Esta ótica também foi corroborada por Donaldson \& Preston (1995), Mitchell, Agle \& Wood (1997) e Davenport (1998).

Freeman (1984) recomenda métodos e modelos em que o gerenciamento propicie 0 atendimento das preocupações dos grupos ou dos indivíduos afetados pelo sistema produtivo da organização, reduzindo os impactos gerados no desenvolvimento de suas atividades. Inicia-se pela análise das mudanças no ambiente em que a organização realiza seus negócios e adoção de respostas no contexto empresarial.

Mitchell, Agle e Wood (1997) afirmam que a teoria das partes interessadas deve levar em conta o poder, a urgência e a legitimidade, não importa o quanto os resultados sejam perturbadores ou desagradáveis. Segundo os autores, os gerentes devem conhecer quais entidades detêm o poder e a intenção de impor sua vontade sobre a organização. Frooman (1999) argumentou que o propósito central desta teoria é entender quem são estes 
interessados e gerenciá-los, formulando estratégicas para respostas às ameaças ou às oportunidades advindas do ambiente.

Portanto, percebe-se que, para gerenciar as partes interessadas, as mudanças devem ser mapeadas, entendidas e os planos de contingências preparados para o caso de ocorrência prejudicial aos interesses da organização. Conforme Pfeffer e Salancik (1978), a organização sobrevive para ampliar seus resultados, sua efetividade deriva do gerenciamento de demandas, em particular vindas de grupos de interesse, os quais dependem de recursos e suporte.

Neste contexto, as organizações necessitam analisar o mapa das partes interessadas, sendo afetadas pelas suas ações e produção de rejeitos. Além disso, gerir as expectativas é um fator chave para assumir uma postura correta. Almeida, Neumann e Sanches (2018) aplicaram a teoria das partes interessadas na relação com resíduos sólidos e PNRS, identificando como componentes principais do mapa de partes interessadas: estado, população, investidores, mídia, funcionários e fornecedores.

O estudo recente realizado por Kabongo e Boiral (2017) mostra que as capacidades para uma ecologia industrial dependem da integração e da coordenação de competências, inovações e novas rotinas relacionadas a diversas áreas funcionais, jogando luz sobre a ótica das capacidades dinâmicas baseadas em recursos naturais. Os autores ofereceram uma compreensão dos fatores necessários para o sucesso da ecologia industrial: inovação e desenvolvimento tecnológico, controle de fluxos de materiais residuais, ajustes em recursos humanos, gestão de restrições ambientais, networking e marketing.

\section{ASPECTOS METODOLÓGICOS}

Trata-se de um estudo de natureza exploratória com abordagem qualitativa, em que o fundamento principal é o aprimoramento de ideias ou a descoberta de intuições. Enquadra-se no grupo de pesquisa prática, porque utiliza conceitos predefinidos e posterior observação de forma ativa dos fenômenos identificados na revisão da literatura. Foi adotada esta estratégia de execução da pesquisa para viabilizar a obtenção dos objetivos. Assim, o foco é compreender como uma organização dispõe sua estrutura, quais suas melhores práticas em termos de processos de oferta de inovação em serviço orientada para gestão de resíduos e quais melhorias são viáveis para o setor industrial da Construção Civil em uma pequena empresa.

Para alcançar o objetivo do trabalho, o método adotado foi o estudo de caso. Ragin e Becker (1992) definiram um caso como uma "fronteira no espaço e tempo" (p.5), significando que se deve limitar por quanto tempo será estudado o caso e se será feito em toda a organização ou em determinados setores. Gerring (2004) argumentou que um estudo de caso pode ser "um estudo intensivo de uma unidade simples com um alvo para generalizar através de um conjunto maior de unidades" (p. 352). Desta forma, para alcançar os resultados em termos de compreensão da estrutura empresarial, melhores práticas e melhorias possíveis, foram feitas duas seções de entrevistas com toda a organização de pequeno porte com altos indícios de inovação disruptiva num espaço de 1 ano.

Seguindo nesta linha de raciocínio, Ragin e Becker (1992) fornecem abordagens para entender os casos como unidade empírica ou construto teórico, classificando-os em específicos ou geral, dependendo da concepção. Nesta concepção de caso como objeto, os "pesquisadores usualmente baseiam-se em designação de caso sobre definições presentes que existem na pesquisa literária" (Ragin \& Becker, 1992, p.10). Sob esta perspectiva, percebe que a literatura relacionou diversas possibilidades de relações entre os temas abordados. Não obstante, a análise dos resultados das entrevistas participativas irá confirmar ou não tais relações.

Gerring (2004) considerou o método do estudo de caso como um desafio empírico. Esta pesquisa acadêmica optou por escolher como unidade de análise uma organização do segmento de serviços para gestão de resíduos sólidos no setor de construção civil. Trata-se de um caso como objeto real (Ragin e Becker, 1992). Classifica-se como um estudo de caso do tipo I baseado em Gerring (2004), não possuindo variação espacial, sendo a coleta de dados realizada apenas em uma unidade em dois momentos. A diferença de tempo entre as entrevistas com os especialistas da organização e gestores foi razoável, conforme mencionado antes.

Segundo Yin (2015), para se delimitar o que será estudado no estudo de caso, faz-se necessário definir a unidade de análise que pode ser um ou mais indivíduos, grupos, organizações, eventos, países ou regiões. 


\subsection{UNIDADE DE ANÁLISE: ORGANIZAÇÃO FORNECEDORA DE SOLUÇÕES SUSTENTÁVEIS (CODINOME ALPHA)}

Conforme mencionado, a escolha da organização para o estudo de caso ocorreu na entrega do prêmio da conferência Sustentar 2014 como parte do $7^{\circ}$ Fórum Internacional pelo Desenvolvimento Sustentável. Este fórum "propõe a promoção de amplo debate de importantes questões socioambientais do planeta, do país e da comunidade" Ecoambiente, 2014, p.1). A organização escolhida foi premiada no $2^{\circ}$ Ranking de Produtos e Tecnologias Sustentáveis, categoria serviços sustentáveis e destaque como pequena e média empresa.

A organização presta serviços para implementação de projetos na gestão de resíduos sólidos em empreendimentos da construção civil. A inovação apresentada pela organização, como destacado na premiação, está na otimização das estruturas de segregação e armazenamento dos resíduos gerados e gestão da diversificada rede de empresas coletoras, atuando junto a elas para aprimoramento de suas práticas.

\subsection{PROCEDIMENTOS METODOLÓGICOS}

Neste trabalho buscou-se, portanto, contribuir para vincular os processos e as práticas vividas pelos pesquisadores nas entrevistas participativas. As perguntas que direcionaram as entrevistas foram feitas para um grupo diversificado de empregados no que tange aos níveis hierárquicos. Foram realizados discussões e comentários em reuniões com os empregados e sócios.

A primeira rodada de perguntas foi realizada no mês de junho de 2014, tendo como principal direcionador compreender em profundidade o que os entrevistados entendiam por responsabilidade social. Quais eram as linhas de serviços presentes nos contratos da empresa? Como percebiam os incentivos para demonstrar sua criatividade e dar sugestões para melhoria de processo, produto ou serviço na empresa? Quais eram os processos da empresa? Como trabalhavam com as partes interessadas? Quais eram os serviços prestados vinculados com a responsabilidade social? Quais treinamentos eram promovidos pela empresa?

Nessa observação participativa das entrevistas, ocorreram interações entre os pesquisadores, os funcionários e os sócios da organização. As perguntas e as respostas foram intercambiadas durante as entrevistas.

Para complementar os resultados das entrevistas, foram realizadas consultas nos documentos presentes nos registros da organização. Estes registros estavam em formato de fotos, contratos e atas de reuniões. Ao término deste estágio, deu-se continuidade à análise das falas dos entrevistados e das novas entrevistas com os sócios da organização, buscando compreender a dinâmica da organização.

Após a primeira fase, foi realizada a segunda rodada de entrevistas. 0 objetivo desta fase era confirmar os resultados obtidos na primeira. Este procedimento encaixa com rigor estudo de caso tipo I de Gerring (2004). Assim, novas questões foram propostas com base nos resultados da primeira rodada e na análise documental. 0 propósito foi saber quais eram os municípios de atuação da organização e como atendia a legislação do município de Belo Horizonte, qual o perfil dos profissionais que disseminavam conhecimento dentro da organização, qual foi o percentual de funcionários que receberam treinamentos ao longo do último ano, como ocorria 0 acompanhamento de desvios operacionais e quais atividades de educação ambiental tinham sido realizadas.

Neste contexto, foi possível observar o antes e o depois dentro da organização. A motivação fundamental era compreender ao longo do tempo as respostas dos entrevistados em função das categorias presentes na revisão da literatura.

\section{ANÁLISE E DISCUSSÃO DOS RESULTADOS}

Visando complementar as informações previamente disponibilizadas pela organização, efetuaram-se a leitura e a análise de documentos internos, propostas comerciais, contratos com clientes e processos organizacionais.

As entrevistas foram realizadas nas dependências da empresa, que possui a peculiaridade de estar localizada em uma área residencial, adaptando uma casa como escritório. Assim, o ambiente de trabalho é idiossincrático, contribuindo para que os empregados se sintam à vontade. Esta liberdade para novas ideias foi observada durante as entrevistas com os engenheiros ambientais e estagiários. 


\subsection{ANÁLISE DOCUMENTAL DA INOVAÇÃO DAALPHA}

Criada em 2009, a Alpha Soluções Sustentáveis foi concebida com o intuito de atuar de forma inovadora no mercado de serviços ambientais, consultoria e sistema de software para gerenciamento de resíduos da construção civil. De acordo com os documentos analisados, os serviços prestados pela empresa estão baseados no conceito da RSC, buscando a redução dos impactos ambientais e a geração de benefícios (econômicos, ambientais e sociais) aos envolvidos. Em suma, os serviços oferecidos pela firma Alpha são:

- Elaboração de planos de gerenciamento de resíduos;

- Consultoria técnica para implantação de sistema;

- Auditoria de sistema de gerenciamento de resíduos;

- Educação ambiental (gerencial e operacional);

- Gestão de condicionantes ambientais para gerenciamento de resíduos;

- Estudos técnicos para implantação de beneficiamento e reciclagem;

- Software on-line para gestão de resíduos.

A empresa engloba gestão no canteiro de obras, sendo este o principal serviço oferecido. Participou do gerenciamento de aproximadamente $150.000 \mathrm{~m}^{3}$ de resíduos da construção civil em empreendimentos de construtoras e instituições diversas. Portanto, a empresa em análise atua como parceira de outras organizações, com o intuito de reduzir o impacto das atividades na cadeia produtiva da construção.

O serviço de gestão de resíduos prestado pela empresa foca no atendimento de requisitos exigidos por certificações PBQP-h (Programa Brasileiro da Qualidade e Produtividade do habitat), ISO 14.001, AQUA e LEED. Estes serviços de gestão suportam 0 atendimento de requisitos legais diretamente relacionados à gestão de resíduos da construção civil, como os apresentados na Resolução/Conama $n^{\circ} 307 / 08$ e na Lei Municipal de Belo Horizonte $\mathrm{n}^{0}$ 10.522/12.

A localidade de atendimento da equipe da empresa é na região metropolitana de Belo Horizonte, Minas Gerais, Brasil. Existem exceções, considerando que o serviço é prestado no canteiro de obras, o que requer visitas técnicas regulares nas localidades dos clientes. Assim, o serviço de apoio remoto é prestado nas obras em diversos estados, utilizando a legislação do município de Belo Horizonte como referência.

O principal serviço prestado da Alpha é a implementação do Plano de Gerenciamento de Resíduos da Construção Civil (PGRCC). Trata-se de um planejamento divido em duas etapas principais: implantação e acompanhamento. O PGRCC tem como foco as soluções práticas para a comunicação entre o setor público e as empresas contratadas pelos clientes da Alpha para transportar os resíduos.

A execução dos processos presente no PGRCC busca identificar os principais problemas e limitações relacionados à gestão de resíduos, tais como dificuldades de acesso, limitação da área do terreno, restrições de horários para transporte por caminhões, pesquisa de prestadores de serviços de transporte e destinação de resíduos.

Além disso, existe uma definição de procedimentos padrão e específicos do empreendimento, levando em consideração a separação dos resíduos. Assim, os resíduos são segregados de acordo com o tipo. Uma tipologia possível é lidar com resíduos de gesso, isopor, madeira e outros materiais que são encaminhados para a reciclagem, aterros sanitários ou reaproveitamento em outras obras.

Neste contexto, a implantação da gestão de resíduos na ótica da Alpha visa preparar o canteiro de obras fisicamente e motivar os envolvidos. Além do acompanhamento no canteiro e da implantação das instalações de apoio, suportando as necessidades diárias dos funcionários, os profissionais da Alpha realizam atividades de capacitação e sensibilização para os colaboradores das empresas que a contratam.

Portanto, o software e os serviços ambientais da Alpha compõem a inovação premiada no tratamento de resíduos sólidos, otimizando os processos de segregação e armazenamento dos resíduos gerados e coletados por seus clientes, resultando em aprimoramento de práticas e processos.

\subsection{ORGANOGRAMA DAALPHA}

A estrutura funcional da empresa apresenta dez colaboradores organizados no organograma inovador 
em formato celular, apresentado na Figura 2. Trata-se de uma estrutura mais orgânica.

A Alpha divide sua hierarquia em células de trabalho. Cabe destacar que um estagiário pode estar em duas células diferentes, porque atua em mais de uma área. A concepção central do organograma considera uma estrutura linear em que nenhum integrante é considerado o chefe dos demais, daí estarem interligados nas palavras do sócio diretor da Alpha.

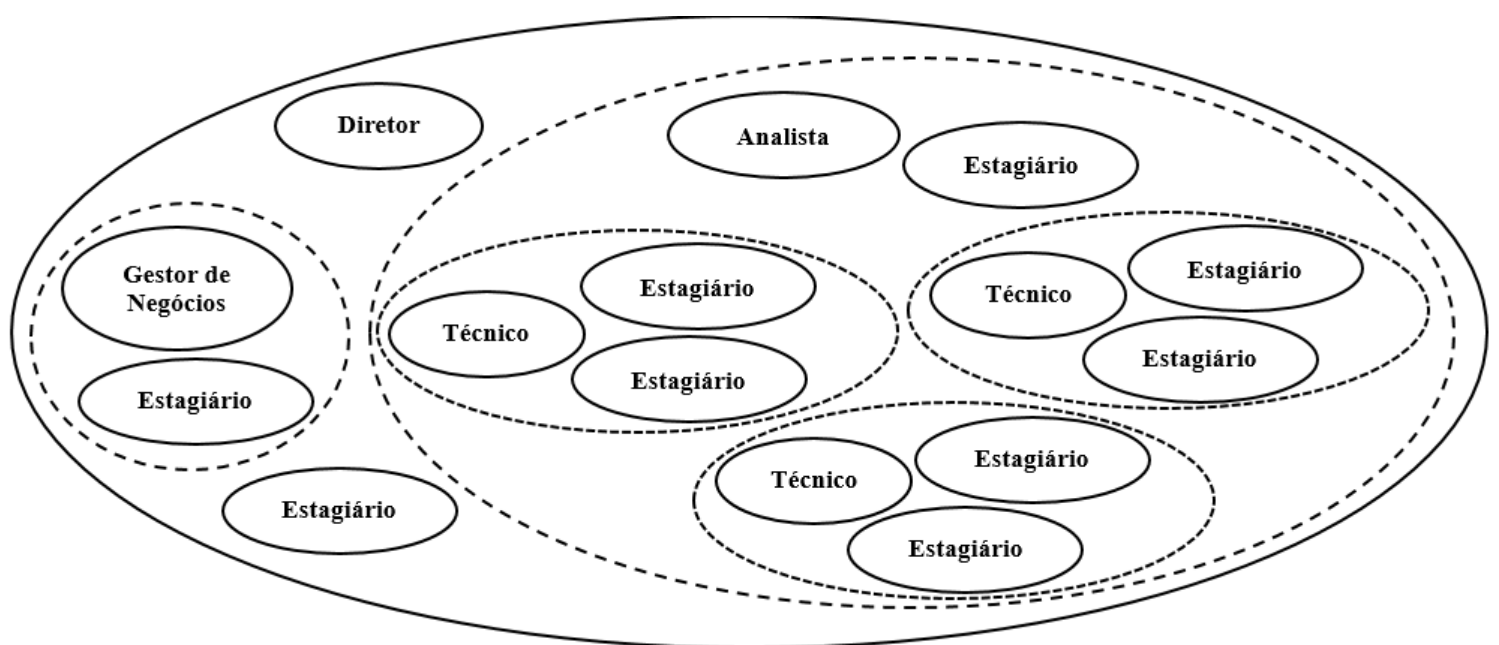

Figura 2. Organograma da Alpha.

Fonte: Elaborada pelo autor.

\subsection{PROCESSOS DE GERENCIAMENTO DAS PARTES INTERESSADAS}

Observou-se nas anotações no diário de bordo dos pesquisadores pela fala dos engenheiros ambientais e dirigentes da Alpha que existe uma estratégia deliberada visando ao envolvimento de todos os interessados no projeto. Trata-se da capacitação contínua. A empresa realiza várias edições do programa de capacitação ao longo da execução da obra em função da integração de novas partes interessadas e diferentes estágios da construção.

Esta capacitação é voltada para os profissionais multiplicadores, formadores de opinião, sendo realizada por meio da dinâmica de grupo e seguida por discussões sobre a gestão de resíduos da empresa cliente.

Considera-se como público multiplicador toda equipe de gestão do empreendimento, entre eles engenheiros, auxiliares, estagiários, mestre, encarregados e outros cargos afins. Nesta perspectiva, observou-se que não havia controle ou qualquer registro sobre a quantidade de pessoas que foram capacitadas por estas dinâmicas em grupo. De acordo com um engenheiro ambiental, a atividade é realizada utilizando jogos empresariais desenvolvidos pela Alpha.

A sensibilização tem foco na comunicação com as partes interessadas, incluindo os profissionais operacionais. Nesta etapa, realizam-se sessões lúdicas e dinâmicas em grupo, como apresentação teatral ou jogos para empresas. Esta sensibilização é realizada para todos os funcionários da obra.

$\mathrm{Na}$ etapa de acompanhamento, verificam-se possíveis desvios operacionais que possam interferir no sucesso do PGRCC, contemplando a atualização constante dos processos relacionados ao gerenciamento de resíduos com o decorrer da evolução das etapas da obra. Este acompanhamento é realizado no site do cliente por meio de visitas periódicas no local da obra ou de forma remota por meio de contatos por e-mail ou telefone. A etapa conta com visitas periódicas de profissionais da Alpha à obra, objetivando coletar dados, corrigir eventuais desvios, identificar melhorias e sugerir ações à organização contratante.

A comunicação é enfatizada durante 0 acompanhamento e são apresentados relatórios periódicos que evidenciam o status do gerenciamento de resíduos no empreendimento, permitindo assim ações corretivas e replicações de boas práticas. A equipe da Alpha desenvolve diversas atividades de educação ambiental focadas no gerenciamento de resíduos da construção civil. Segundo informações fornecidas pelos entrevistados, atualmente há mais de 50 tipos de atividades, entre elas palestras, dinâmicas de grupo, jogos e instruções técnicas. 
Ao serem questionados se sabiam qual a dinâmica empresarial da Alpha e como é feita a gestão das partes interessadas, foi mencionado por um analista ambiental que a empresa atua em um sistema de compilação de dados, buscando qualidade no gerenciamento desses resíduos para seus clientes. Percebe-se que as respostas foram dadas levando em consideração a rotina operacional.

Observou-se que os entrevistados direcionaram suas explicações sobre o software ou sistema de informação que a Alpha comercializa. Este produto faz uma agregação dos dados dos clientes para oferecer relatórios com informações que ajudam as contratantes realizarem gerenciamento dos seus rejeitos. A discussão ficou em torno da perspectiva dos clientes da Alpha. Neste contexto, observou-se o vínculo de partes interessadas somente com a ótica dos clientes.

Neste ponto, resgatando a teoria das partes interessadas, foi explicada para o grupo de entrevistados a importância em identificar e analisar todas as pessoas, os grupos ou as organizações que mantêm relação direta ou indireta com a empresa. Foi informado aos entrevistados que essa prática, de identificar quem são, como atua e os principais problemas que podem surgir, permite à organização a possibilidade de criar estratégias para minimizar os impactos negativos e otimizar os impactos positivos. Após esta explicação, os entrevistados comentaram que não havia um mapa formal das partes interessadas.

Foi perguntado se acreditavam que a Alpha buscava trabalhar com suas partes interessadas. Os entrevistados comentaram que tinham mapeado as necessidades de órgãos públicos, clientes, transportadoras e comunidade. Este seriam os principais afetados pela gestão dos resíduos. Desta maneira, a Alpha se preocupava com as partes interessadas dos clientes e não com as suas próprias.

Destaca-se a existência de uma relação conflitante gerada por divergências de interesses. Foi comentado pelo grupo de entrevistados que a necessidade de retirada de entulhos do canteiro de obras com agilidade e um bom relacionamento com os fornecedores configuram um equilíbrio desejável entre as partes, mas é incompatível.

Outra necessidade de gestão das partes interessadas foi verificada em relação aos locais corretos de descarte dos materiais, e os gastos com segurança no transporte afetam a lucratividade do fornecedor. Entretanto, o cuidado com o meio ambiente é um interesse da comunidade. Sendo assim, as expectativas dos fornecedores e da comunidade são importantes para o sucesso na gestão das partes interessadas dos clientes da Alpha.

Neste ponto da entrevista, os integrantes da empresa perceberam uma oportunidade para sair do gerenciamento informal com as partes interessadas para um processo proativo. 0 grupo manifestou interesse no assunto e a possibilidade de desenvolvimento de futuras atividades para a organização gerenciar suas partes interessadas.

Observou-se uma preocupação da empresa com relação as suas partes interessadas não legítimas. Freeman (1984) conceitua as partes interessadas não legítimas como aquelas consideradas sem muito poder, mas que podem criar problemas para as organizações. AAlpha tem buscado adotar um gerenciamento das partes interessadas mais baseado na vivência prática e não no conceito do autor.

Para gerenciar as partes interessadas, as mudanças devem ser mapeadas, entendidas e os planos de contingências preparados para 0 caso de ocorrência prejudicial aos interesses da organização. Durante a entrevista, foi apontado que, apesar de não ter um mapa dos interessados, a Alpha tinha uma preocupação em comunicar-se constantemente com os envolvidos nas atividades do dia a dia. Em especial, quando estavam desenvolvendo atividades nas instalações dos seus clientes.

\subsection{ANÁLISE DO CONCEITO DE RESPONSABILIDADE SOCIAL CORPORATIVA}

Foi apresentada ao grupo de entrevistados a questão referente ao entendimento do significado de RSC. O grupo comportou-se de forma concisa e todos fizeram apontamentos que remetem ao quarto nível da pirâmide de Carrol (1991), a filantropia, portanto não compreendendo que é preciso passar pelos primeiros antes de chegar ao topo da pirâmide.

[...] A responsabilidade social, no meu entendimento, é a relação social da empresa com seu entorno, com a sociedade.

Após as exposições do grupo, o pesquisador explicou o conceito com base na pirâmide, comentando sobre a parte econômica, legal, ética e filantrópica. Percebeu-se a falta de conhecimento em relação à necessidade 
de atender os níveis inferiores para galgar os superiores.

Um entrevistado apresentou dúvidas em relação ao cargo que ocupava na Alpha. Mencionou que não sabia se era um Analista Ambiental. Este fato remeteu à importância da análise dos papéis e das responsabilidades dos funcionários. Observou-se a necessidade da Alpha manter maior diálogo e comunicação explícita entre seus colaboradores para evitar equívocos. A discussão evoluiu e a solução pensada no momento foi a identificação e a formulação de expectativas mútuas entre a empresa e os seus trabalhadores. Assim, os conceitos da RSC, no que tange à sua dimensão interna, relacionados com os colaboradores, deveriam ser comunicados com clareza.

Dando prosseguimento, questionou-se sobre o fornecimento de serviços vinculados com a RSC. Conforme um Analista Ambiental:

[...] as empresas, ao buscarem sustentabilidade, procuram a Alpha para ajudar [...] elas querem utilizar nossa consultoria para realizar ações que melhoram seus processos na gestão de resíduos.

As construtoras buscam formas para reduzir o desperdício, o que leva à redução de custos e ao desenvolvimento de ações ambientais. Estas ações estão no escopo de prestação de serviços da Alpha e são realizadas por meio da formulação do plano de gerenciamento dos resíduos, utilizando o software da Alpha.

A estratégia para RSC na Alpha foi analisada e percebida em função do valor que seus produtos e serviços possuem para sustentabilidade, por meio do plano de gerenciamento de resíduos, o qual propõe implantação, acompanhamento e fornecimento de mecanismos de comunicação entre o setor público e as empresas subcontratadas dos seus clientes no transporte dos resíduos. Esta estratégia foi premiada no $7^{\circ}$ Fórum Internacional pelo Desenvolvimento Sustentável, o que corrobora com a proposta de Stamm e Trifilova (2009), quando afirmaram que o futuro da inovação se relaciona com a preservação ambiental.

Nesta linha de raciocínio, outro fator enfatizado nesta discussão analítica sobre a Alpha é a diferença nos conceitos e nos termos utilizados por seus funcionários. Conforme mencionado, Carrol (1991) mencionou que a RSC se refere ao econômico, legal, ético e filantrópico. Em relação à sustentabilidade, os pilares têm alicerce na criação de valor ao longo prazo, derivando do desenvolvimento econômico, ambiental e social definido por Elkington (1997). As entrevistas indicam que, para os funcionários da Alpha, a sustentabilidade era pensada apenas na questão ambiental e social, beneficiando a comunidade na gestão dos resíduos.

\subsection{ANÁLISE DOS PROCESSOS ORGANIZACIONAIS}

Em seguida, foi exposta a pergunta que buscava entendimento sobre os contratos firmados pela empresa sobre as ofertas de serviços presentes nos contratos com os clientes. As respostas indicaram que a empresa realizava "projetos" e "melhorias".

De acordo com os entrevistados:

[...] o escopo dos contratos da Alpha com seus clientes temos cláusulas que permitem implantar e acompanhar seus projetos. [...] Mas, tem muita dificuldade na execução do escopo dos contratos no canteiro de obras dos clientes. [...].

Na sequência, foi possível observar que as práticas podem ser melhoradas, em especial no que tange aos contratos entre a empresa e os seus clientes.

[...] existem dois modelos de contratos, um do cliente e outro da Alpha, o nosso nós conhecemos, o do cliente não.

Desta forma, percebe-se que os contratos assinados com os clientes ficam no nível da administração da empresa. Um estagiário comentou que o principal serviço da Alpha era "projeto", esta era a forma como ele percebia o negócio da Alpha. Outros analistas ambientais mencionaram a palavra "consultoria" com frequência.

Estas falas, de certa forma, demonstraram a existência de lacunas na comunicação dos colaboradores ao fornecerem detalhamento sobre os negócios da organização, o que reforça a percepção da necessidade de aperfeiçoamento da comunicação na organização, proporcionando aos colaboradores as informações que necessitam sobre a organização, o posto de trabalho e a forma de trabalho. 
Dando prosseguimento, visando entender as atividades desenvolvidas na organização, questionaram-se quais eram os processos ou as iniciativas principais da Alpha. Ao responderem este questionamento, os entrevistados mencionaram a existência de dados sobre saída de resíduos que são adquiridos nas obras e as informações são geradas para apoiar o processo de tomada de decisões referentes ao gerenciamento dos resíduos.

De acordo com alguns analistas, as questões referentes ao local de destino e à quantidade transportada são incluídas em relatórios de acompanhamento para documentação legal e apoio ao cliente. São disponibilizadas informações extraídas de dados brutos vinculados a quem fez o transporte e qual o tipo de resíduo transportado. Entretanto, não existe um repositório computacional que consolide e agrupe as informações dos diversos clientes.

\subsection{ANÁLISE DO PROCESSO DE GESTÃO DA INOVAÇÃO}

A primeira pergunta feita sobre inovação teve foco na criatividade e na abertura para receber opiniões sobre melhorias nos processos da empresa. $O$ objetivo foi compreender se existiam incentivos para demostrarem criatividade e dar sugestões para melhoria de processo, produto ou serviço da Alpha. A resposta foi unânime.

[...] Sim, com certeza, eles pedem opinião para todos e escutam essas sugestões. Até incentivam. [...] Em outras empresas não acontecia isso, não era possível dar sugestões de melhoria para. Aqui, na Alpha, isto é incentivado".

Uma observação importante foi evidenciada pela intervenção de uma analista ambiental que indagou

[...] até que ponto é bom poder fornecer opiniões?

Questionada sobre o que queria dizer com o questionamento, ela argumentou dizendo que:

[...] algumas vezes, tenho receio para falar.

Na sequência, outro Analista Ambiental mencionou:

[...] essa abertura que a empresa fornece para nossas opiniões pode ser devido ao fato de ser um serviço novo no mercado. [...] Seu receio deve ser porque pedem sua opinião com frequência.

Todos os outros entrevistados concordaram com essa afirmação. Um dos analistas lembra que se trata de um "papel de consultoria" da empresa. Os processos, os dados e as informações trabalhadas são decorrentes do tipo de contrato firmado com os clientes. Ele acrescentou que os serviços de consultoria prestados pela firma Alpha estão em um estágio inicial porque fornecem recomendações básicas de como realizar o gerenciamento dos resíduos.

Entretanto, foi observado na fala dos entrevistados que existe a busca por novos horizontes nos serviços prestados. Ocorre 0 interesse em atuar no segmento de governo e captar oportunidades em relação ao gerenciamento dos aterros sanitários pelos municípios. Segundo um analista ambiental, esta possibilidade é vista como um futuro promissor para Alpha.

Os entrevistados foram questionados sobre o fornecimento de treinamentos promovidos pela Alpha. Todas as respostas foram "sim". Os entrevistados disseram que receberam treinamentos subsidiados pela empresa. A agenda destes treinamentos estava vinculada aos interesses dos funcionários em conjunto com 0 negócio da empresa.

Por iniciativa própria, os entrevistados mencionaram a questão do mentor (padrinho), explicando que, quando um novo funcionário entra na Alpha, um mentor é designado para ele. Constatou-se que os funcionários buscavam novos conhecimentos, tanto no setor de atuação da empresa como em outros. Assim, observa-se a relação entre realizar treinamentos e sugestões dos mentores.

A média da faixa etária dos empregados da Alpha era 22 anos e as expectativas de progresso na carreira 
era um fator determinante na sua motivação, segundo eles.

Os treinamentos eram feitos com afinco por todos nós, buscando crescimento profissional. [...] Em termos de reconhecimento e premiação, a empresa tem motivado bastante o pessoal. [...] melhorou muito e os treinamentos vêm acontecendo com maior frequência.

Comentaram que existem as confraternizações e fizeram menção ao "funcionário destaque do mês" como forma de reconhecimento cíclico.

Referente ao valor agregado da inovação, um dos sócios entrevistados da Alpha comentou que:

[...] dentro da Alpha, o crescimento e o envolvimento na realização de projetos 'acabou' obtendo prioridade, deixando em segundo plano a inovação e novos desenvolvimentos. [...] estamos tentando retomar.

Percebeu-se na fala deste entrevistado que inciativas buscando novas formas de agregar valor ao negócio da empresa estão sendo retomadas. Segundo ele,

[...] o desafio é manter o ritmo constante de inovação paralelamente ao crescimento da empresa e a realização das atividades corriqueiras relacionadas aos projetos em andamento.

Ao analisar a documentação fornecida pela Alpha, percebeu-se que os benefícios gerados pela inovação, contribuindo para a empresa ganhar prêmios, foram no âmbito ambiental, redução dos impactos da construção civil e resíduos gerados por este setor industrial.

Os pontos fortes desta inovação apoiam a otimização da destinação dos resíduos, reaproveitamento, reciclagem, desenvolvimento de fornecedores, redução de risco, aumento da produtividade, sensibilização dos colaboradores, redução de custos com aquisição de materiais, transporte e disposição de resíduos, limpeza e organização do canteiro de obras. A Alpha apoiou a criação de empresas para trituração dos resíduos de madeira gerados nas obras de seus clientes.

Outro ponto evidenciado foi a falta de gestão do conhecimento. Não existia um repositório de lições apreendidas, alguns entrevistados mencionaram que o conhecimento estava "apenas na cabeça". As lições aprendidas nos projetos ou serviços prestados para os clientes não eram disseminadas para outros setores da empresa, a não ser quando necessitavam de alguma informação de imediato.

\section{CONSIDERAÇÕES FINAIS}

Conclui-se que a ecoinovação ocorre nas combinações de serviços da firma estudada, porque sustenta a transformação da falha ambiental ocasionada por ações de mal descarte dos resíduos em agregação de valor no âmbito socioambiental. Em síntese, pode-se considerar como um método disruptivo, tendo em vista a natureza do prêmio alcançado, mudanças nos processos de armazenamento dos resíduos e gestão da rede coletora.

Observou-se a possibilidade de melhoria na estrutura da firma, em especial, na gestão do conhecimento no que se refere às lições aprendidas. Recomenda-se desenvolver uma base de dados estruturada que configure e gerencie as experiências e as vivências dos funcionários nos projetos, criando novas ecoinovações. Assim, 0 compartilhamento das soluções de problemas, sejam de sucesso ou fracasso, poderá apoiar melhorias na estrutura, aumentando 0 aprendizado.

Melhor comunicação e fluxo de informação entre e dentre as partes interessadas poderão aumentar a integridade nos contratos com clientes. Cláusulas alinhadas com a estratégia RSC das firmas contratantes devem ser mais acessíveis. Esta conduta prática poderá melhorar o acompanhamento e a execução das atividades típicas da gestão ambiental, possibilitando melhor conhecimento do resultado esperado pelos envolvidos. Infere-se que atividades em equipe, treinamentos internos e externos reforçam a comunicação entre as partes interessadas, estabelecem regras para o job-to-be-done e aprendizado compartilhado.

Trabalhos futuros podem analisar a aplicação da gestão do conhecimento e a relação com a ecoinovação, permitindo descobrir como a difusão do conhecimento influencia no processo de ecoinovação na gestão de 
resíduos sólidos. Outro estudo poderia observar questões envolvendo oportunismo e racionalidade, que é limitada em contratos operados pelas firmas atuantes no setor ambiental.

\section{REFERÊNCIAS}

Almeida, R. G., Neumann, M., \& Sanches, S. L. R. (2018). O que é evidenciado no Brasil sobre a Responsabilidade Social Corporativa advinda da Política Nacional de Resíduos Sólidos (PNRS) nos Formulários de Referência e Relatos Integrados? Sociedade, Contabilidade e Gestão, 13(3).

Bakker, F. G. A., Groenewegen, P., \& Hond, F. D. (2005). A bibliometric analysis of 30 years of research and theory on corporate social responsibility and corporate social performance. Business \& Society, 44(3), 283-317.

Barnard, C. I. (1971). As funções do executivo. São Paulo: Atlas.

Beck, U. (2010). Sociedade do risco (1st ed.). São Paulo: Editora 34.

Bowen, H. R. (1953). Social responsibilities of the businessman. New York: Harper and Brothers.

Brundtland, G. H. (1987). Our Common Future - Brundtland Report. Report of the World Commission on Environment and Development. Oslo, Norway.

Carrol, A. B. (1991). The pyramid of corporate social responsibility: toward the moral management of organizational stakeholders. Business Horizons, 34(4), 39-48.

Carrol, A. B., \& Buchholtz, A. K. (2006). Business \& society: ethics and stakeholder management (6th ed.). Manson, Ohio: South-Western.

Davenport, T. H. (1998). Putting the enterprise into the enterprise system. Harvard Business Review.

Donadon, F. A. B., \& Santos, D. F. L. (2018). A relevância da eco-inovação para resíduos sólidos na agroindústria da fruticultura. Revista Gestão \& Tecnologia, 18(3), 225-246.

Donaldson, T., \& Preston, L. E. (1995). The stakeholder theory of the corporation: concepts, evidence, and implications. The Academy of Management Review, 20(1), 65-91.

Ecoambiente. (2014). Informação socioambiental construindo a sustentabilidade. Retrieved November 9, 2015, from http://oecoambiental.blogspot.com.br/2014/05/vcongresso-brasileiro-de-gestao.html

Elkington, J. B. (1997). Cannibals with forks: the triple bottom line of 21st century business. Oxford: Capstone Publishing Ltd.

Ferreira, A. (2018). Gestão de resíduos sólidos urbanos em municípios do Paraná. Revista Capital Científico Eletrônica (RCCe), 16(2).

Freeman, R. E. (1984). Strategic management: s stakeholder approach. Marshfield, Massachusetts: Pitman.

Friedman, M. (1984). Capitalismo e liberdade. São Paulo: Editora Abril Cultural.

Frooman, J. (1999). Stakeholder Influence Strategies. Academy of Management Review, 24(2), 191-205.

Gerring, J. (2004). What Is a Case Study and What Is It Good for? American Political Science Review, 98(2).

Govindarajan, V., \& Trimble, C. (2005). Building Breakthrough Businesses within Established Organizations. Harvard Business Review, 8(5), 58-68.

Habib, A., \& Bhuiyan, M. B. U. (2017). Determinants of monetary penalties for environmental violations. Business Strategy and the Environment, 26(6), 754-775. https://doi.org/10.1002/bse.1947

Kabongo, J. D., \& Boiral, O. (2017). Doing More with Less: Building Dynamic Capabilities for Eco-Efficiency. Business Strategy and the Environment, 26(7), 956-971. https://doi.org/10.1002/bse.1958

Kanter, R. M. (1999). From spare change to real change: the social sector as beta site for business innovation. Harvard Business Review, 77(3), 122-132.

Mdic [Ministério do Desenvolvimento, Indústria e Comércio Exterior] . (2015). Parques tecnológicos e incubadoras. Retrieved October 27, 2015, from

http://www.mdic.gov.br//sitio/interna/interna.php?area=3\&menu=3614 
Maiello, A., Britto, A. L. N. de P., \& Valle, T. F. (2018). Implementação da Política Nacional de Resíduos Sólidos. Revista de Administração Pública, 52(1), 24-51.

Mitchell, R. K., Agle, B. R., \& Wood, D. J. (1997). Toward a theory of stakeholder identification and salience: defining the principle of who and what really counts. The Academy of Management Review, 22(4), 853-886.

NorrmanN, C., \& Bager-Sjögren, L. (2010). Entrepreneurship policy to support new innovative ventures: Is it effective? International Small Business Journal, 28(6), 602-619.

Penrose, E. (1959). The theory of the growth of the firm (Fourth). Oxford: Oxford University Press.

Pfeffer, J., \& Salancik, G. (1978). The external control of organizations. New York: Harper and Row.

Radu, C., \& Francoeur, C. (2017). Does Innovation Drive Environmental Disclosure? A New Insight into

Sustainable Development. Business Strategy and the Environment, 26(7), 893-911.

https://doi.org/10.1002/bse.1950

Ragin, C. C., \& Becker, H. S. (1992). What Is a Case?: Exploring the Foundations of Social Inquiry (0011-New e ed.). Cambridge England ; New York, NY, USA: Cambridge University Press.

Schumpeter, J. A. (1934). The theory of economic development: an inquiry into profits, capital, credit, interest, and the business cycle. Cambridge: Harvard University Press.

Silva, C. L. da, \& Biernaski, I. (2018). Planejamento e Gestão de Resíduos Sólidos Urbanos: Um Estudo de Caso na Região Metropolitana de Belo Horizonte à Luz da PNRS. Gestão \& Regionalidade, 34(101).

Stamm, B., \& Trifilova, A. (2009). The future of innovation. Surrey: Gower.

Tidd, J., Bessant, J., \& Pavitt, K. (2005). Gestão da inovação. Porto Alegre: Bookman.

Tödling, F., \& Kaufmann, A. (2001). The role of the region for innovation activities of SMEs. European Urban and Regional Studies, 8(3), 203-215.

Trumpp, C., \& Guenther, T. (2017). Too Little or too much? Exploring U-shaped Relationships between Corporate Environmental Performance and Corporate Financial Performance. Business Strategy and the Environment, 26(1), 49-68. https://doi.org/10.1002/bse.1900

Tsai, K.-H., \& Liao, Y.-C. (2017). Sustainability Strategy and Eco-Innovation: A Moderation Model. Business Strategy and the Environment, 26(4), 426-437. https://doi.org/10.1002/bse.1926

Veeraraghavan, V. (2009). Entrepreneurship and innovation. Asia-Pacific Business Review, 5(1), 14-20.

Walsh, P. R., \& Dodds, R. (2017). Measuring the Choice of Environmental Sustainability Strategies in Creating a Competitive Advantage. Business Strategy and the Environment, 26(5), 672-687.

https://doi.org/10.1002/bse.1949

Yadav, P. L., Han, S. H., \& Kim, H. (2017). Sustaining Competitive Advantage Through Corporate Environmental Performance. Business Strategy and the Environment, 26(3), 345-357. https://doi.org/10.1002/bse.1921

Yin, R. K. (2015). Estudo de Caso: Planejamento e Métodos. Porto Alegre: Bookman. 